City University of New York (CUNY) CUNY Academic Works

2020

\title{
Universal Gravitation and Circular Motion
}

Xin Gao

CUNY La Guardia Community College

\section{How does access to this work benefit you? Let us know!}

More information about this work at: https://academicworks.cuny.edu/lg_oers/111

Discover additional works at: https://academicworks.cuny.edu

This work is made publicly available by the City University of New York (CUNY).

Contact: AcademicWorks@cuny.edu 


\section{Lab 3 Universal Gravitation and Circular Motion}

\section{Objectives}

This is designed to serve as a pre-lab. Students will be asked to watch the videos provided below before the lecture and complete a worksheet with thought- provoking questions guiding them to relating circular motion with the motion of a satellite or planet, and then think about what force is serving as the centripetal force for planets when they move around the sun. Students will also be prompted to think about whether or not there is really no gravity in space, so as to realize how misleading those terms, such as "weightless" or "zero gravity in space" are.

\section{Supplies}

- Glass of Wine video https://www.youtube.com/watch?v=FM1Y6tROWEo

- Satellite around the Earth video https://www.youtube.com/watch?v=sj7zsGkpZxg

- Simulation of Planets around the Sun video https://www.youtube.com/watch?v=z8aBZZnv6y8

\section{Procedure}

Watch the videos using the links listed above and complete the worksheet below.

\section{Questions}

1. After watching the three videos, can you identify anything in common with these videos? What kind of motion are the glass of wine, satellite, or the planets doing?

2. If you hold a glass of wine, satellite/planet model up above your head and release it, what will happen? Explain why. Does it happen to them in the video? If not, try to explain why. 
3. What makes things fall when holding them up above your head and release them in the air? Does this force still exist high up above the earth where satellites are usually located? If yes, why don't satellites fall?

4. In the Glass of Wine experiment, what are the necessary conditions for the glass of wine move above head without spilling or falling? Can it happen without the man holding the string hard and pulling the string hard? What is the direction of the force applied on the glass of water when it moves around? Is there any force acting on the satellite when it goes around the earth? What is the force and where is the force from?

5. What are the necessary conditions for planets to go around the sun without falling? Is there a force required? If yes, what kind of force it is and where is the force from?

\section{First and last name:}

\section{Copyright:}

This work is licensed under a Creative Commons Attribution 4 International License. 